\title{
The Relationship Of Learning Orientation To Organizational Performance
}

Robert Preziosi (E-mail: preziosi@huizenga.nova.edu), Nova Southeastern University Heidi M. McLaughlin (E-mail: hmclaughlin@mail.barry.edu), Barry University

Gregory C. McLaughlin (E-mail: gmclaug@aol.com), Human Performance Metrics

\begin{abstract}
The fundamental premise of successful firms possessing resources that are superior to those of their competitors has been prevalent in the related literature. This has fostered a wealth of research to determine the source, as well as the necessary maintenance of these resources. Resources should possess certain characteristics that would benefit the firm, given that effective strategic deployment of resources at any time is moderated by time, the actions of competitors, and the dynamics of the external environment.
\end{abstract}

It is through this ongoing process of competing and ultimately succeeding through ideocyncratic resources that provides the catalyst for superior financial performance. These capabilities, which are developed over time, provide a source of advantage that must be continually protected and improved. As the external environment changes, dynamism in the environment requires a departure from established organizational strategies; the entrepreneurial firm pursues competitive advantage through innovation, considered essential to competitive advantage. The competitive marketplace becomes the impetus for innovation, and innovation in turn becomes a key form of organizational learning.

\section{Introduction}

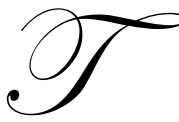

he fundamental premise of successful firms possessing resources that are superior to those of their competitors has been prevalent in the related literature. This has fostered a wealth of research to determine the source, as well as the necessary maintenance of these resources. Resources should possess certain characteristics that would benefit the firm, given that effective strategic deployment of resources at any time is moderated by time, the actions of competitors, and the dynamics of the external environment.

It is through this ongoing process of competing and ultimately succeeding through ideocyncratic resources that provides the catalyst for superior financial performance. These capabilities, which are developed over time, provide a source of advantage that must be continually protected and improved. As the external environment changes, dynamism in the environment requires a departure from established organizational strategies; the entrepreneurial firm pursues competitive advantage through innovation, considered essential to competitive advantage. The competitive marketplace becomes the impetus for innovation, and innovation in turn becomes a key form of organizational learning.

Contemporary research focuses on the integration and identification of the components of organizational learning necessary for a firm to achieve competitive advantage as indicated by performance levels.

This study incorporates the constructs of learning orientation as they relate to organizational performance. Although organizational performance is the ultimate measure of the existence and effectiveness of the three organizational learning components (commitment to learning, shared vision and open-mindedness) on organizational performance. This study compares all three components, in addition to a new measure of short term performance, dynamism, on a cross sectional analysis of industries. 
Research findings indicate a positive linear relationship between performance and marketing orientation, and market orientation and learning orientation. The construct of innovation did not correlate to performance, learning orientation or market orientation. Market dynamism did exhibit a positive linear relationship to performance. The results complement the research of Sinkula, Baker, and Noordewier (1997) and Baker and Sinkula (1999).

\section{Literature Review}

As a firm develops, an historical path of strategic deployment decisions become ingrained as an organizational paradigm and serves to guide future approaches (Nelson \& Winter 1982, Barney 1991, Grant 1991, Moorman \& Miner 1997). This has been referred to in the literature as organizational learning (Cyert \& March 1963, Nelson and Winter 1982, Levitt and March 1988, Cohen and Levinthal 1990). However, two disparate views of this routinized behavior have surfaced; one, that path dependent organizational behavior may be what prevents a firm from achieving competitive advantage (Levitt and March 1988, Dickson 1992, Leonard-Barton 1992) by becoming inflexible and incapable of abandoning established strategy (Moorman and Miner 1997). Two, an organization which adapts to its environment by utilizing static, memory generated strategies is not engaging in a learning process at all; the reliance on previously applied approaches would be considered simply problem solving, and, thus, not requiring new insights, and, therefore, not requiring learning (Hedberg 1981, Cavaleri 1994).

The root cause of this development is the inherent and inevitable existence of environmental turbulence which will affect the value and relevance of prescribed strategic approaches (Achrol 1991, Glazer 1991, Hedberg 1981, Moorman and Miner 1997).

Turbulence, therefore, effectively erodes any benefit provided by what an organization historically accumulates as learning (El Sawry, Gomes and Gonzalez 1986, Moorman and Miner 1997). Dynamism in the environment in which the organization operates may then cause the firm to 'unlearn' its entrenched strategies to successfully respond to the present uncertainty (Cyert and March 1963, Starbuck 1976, Hedberg 1981). This unlearning process is exacerbated by the reliance and comfort of successful strategies in the past, as the firm evolves from a stable environment to a more hostile existence (Starbuck and Hedberg 1977, Argyris and Schon 1978, McGill and Slocum 1992).

The revelation of organizational learning as a developing resource, versus capabilities and resources developed over a firms' history, has caused a need for researchers to redefine organizational learning. What must be identified is the source of learning beyond the long held presumption of ideocyncratic capabilities from resources inherent in a firms' history (Dodgson 1993, Collis 1994). This evolution of thought was initially presented as early as 1934 by Joseph Schumpeter and indicates a departure from the fundamentally Ricardian focus of RB theory presented by Penrose (1959). The Ricardian perspective evident in the RB theory is the inherent value of scarce resources that invariably provide an organization with an advantage over its' competitors (Ricardo 1817). The value is in the form of 'rents' or returns above the resource owners' opportunity costs (Mahoney and Pandian 1992). This Ricardian premise is manifested in the contemporary literature discussions of ideocyncratic resources and causal ambiguity, which through their inimitable properties would provide a source of competitive advantage. The literature regarding this phenomenon is reverting to a more Schumpeterian perspective that was the precursor to the RB theory of Penrose (1959).

Schumpeter advocated that rent could be achieved not by established resources necessarily, but by a more entrepreneurial and risk tolerant approach to marketplace challenges and uncertainties (Schumpeter 1934, Rumelt 1984, Mahoney and Pandian 1992). This positions competition to encourage 'creative destruction' of previous sources of competitive advantage (Collis 1994). Also referred to as 'Schumpeterian shocks' (Rumelt and Wensley 1981, Barney 1991), the act of departure from established organizational strategies provides the entrepreneurial firm with a source of competitive advantage through the use of innovation, which is theorized to be sustainable over the long term and essential to competitive advantage (Hunt and Morgan 1995). This perspective is evident in the basic premise of RB theory; this Schumpeterian approach views the presence of competition as a dynamic influence in the evolution of new resources given an uncertain environment (Mahoney and Pandian 1992). The competitive 
marketplace then becomes the impetus for innovation, and innovation in turn becomes the key form of organizational learning (Nonaka 1994). Learning is defined as a new response or action (Daft and Weick 1984, Argyris and Schon 1978) once an interpretation of the environmental challenge has been determined (Daft and Weick 1984). This sense of 'discovery' and change (Schumpeter 1934, Hayek 1978, Kirzner 1979) through subsequent innovations is considered 'new' learning (McGill and Slocum 1992), which becomes a source of inimitable capabilities within the innovative firm (Mahoney 1995). Thus, firms learn via innovation through the ubiquitous presence of competition (Hayek 1935, Hunt 1997). The requisite ability of a firm to innovate in an attempt to supercede its competitors is the core premise of competitive advantage, indicated by superior financial performance (Hunt 1997).

Since innovative capabilities signal an organizations' ability to produce new learning, and since all organizations may not possess this ability equally, future rent streams will be superior for the greatest innovator (Liebeskind 1996), thus providing a competitive advantage. Therefore, the level of environmental change triggers a firms' need to abandon its previous strategies in the interest of innovation (Moorman and Miner 1997).

\subsection{Theoretical Framework}

Contemporary research focuses on the integration and identification of those variables necessary for a firm to achieve competitive advantage as indicated by performance levels. These variables are identified as learning orientation, market orientation and innovation based on the research of Narver and Slater (1990, 1994), Jaworski and Kohli (1993), Baker, Sinkula and Noordewier (1997), Baker and Sinkula (1999), and Hurley and Hult (1998).

Learning orientation is considered a higher-level construct (Sinkula, Baker and Noordewier 1997) that provides the organization with the capabilities of creating and maintaining competitive advantage (Day 1991, Dickson 1996) through an ability to challenge established organizational norms as the environment changes (Baker and Sinkula 1999). This ability to respond to environmental changes is one of the core competencies an organization must develop and maintain to achieve competitive advantage and superior performance (Slater and Narver 1996, Sinkula, Baker and Noordewier 1997); generative learning serving as one of the essential core competencies (Sinkula, Baker, Noordewier 1997, Baker and Sinkula 1999).

Organizational learning, as a core competency (Day 1991, Dickson 1996, Slater and Narver 1996, Baker, Sinkula and Noordewier 1997, Baker and Sinkula 1999) serves as a conduit to an innovation orientation (Hurley and Hult 1998).

\subsubsection{Statement Of The Problem}

As the attempts to define organizational learning and its impact on performance continues to be discussed in the available literature, this discourse has given rise to a derivative theory, RB or Resource Based theory. (Hunt and Morgan 1995, Hunt 1997). Hunt and Morgan have synthesized RB theory (Penrose 1959) to include the influence of competitive firm behavior in the firms' pursuit of competitive advantage, hypothesized to yield superior financial performance (Hunt 1997). The basic elements of RB theory specifically identify the presence of inimitable resources which can be eroded by competition over time (Schumpeter 1934). Thus, resources must be continually developed (Grant 1991) as established organizational paradigms are made obsolete by market changes (Cyert and March 1963, Starbuck 1976, Hedberg 1981, El Sawry, Gomes and Gonzalez 1986, Moorman and Miner 1997). This dynamic process of developing resources that continually yield positions of market superiority despite the actions of competitors describes the need and endogenous nature of innovation (Hunt 1997). The major flaw in the existing literature regarding firm resources as they relate to competitive advantage is the lack of isolation of those components within the firm, which enable the organization to sustain any level of competitive advantage (Teece, Pisano and Schuen 1997). The outcomes of learning, now defined as innovations are identified (superior financial performance); but how these outcomes are achieved remains open for analysis (Dodgson 1993).

Therefore, it is theorized that the presence of both a market orientation and learning orientation (manifested as innovation) provide a synergistic effect upon firm performance, with learning orientation as the primary source of 
higher order, or double loop learning (Argyris and Schon 1978, Senge 1990, Sinkula 1994, Slater and Narver 1995). The presence of a learning orientation affects the firms' ability to possess double loop learning as a core competency (Sinkula, Baker and Noordewier 1997).

\subsubsection{Research Question}

Market orientation has evolved into essentially a learning orientation (Slater and Narver, 1997). Being market driven theoretically assumes anticipatory capabilities by the firm to introduce products and services in response to customer needs, thus impacting organizational performance (Hurley and Hult 1998). Is there a relationship between learning orientation and performance?

\subsubsection{Justification}

Learning orientation and innovation have been more clearly defined in terms of the levels a firm may exhibit as well as the correlation of these constructs to one another. Research on learning orientation has evolved from the early propositions of single loop and double loop learning (Argyris and Schon 1978, Senge 1990) to present day attempts to isolate the extent to which a learning orientation can contribute to either single loop (or adaptive behavior) or double loop (generative behavior) (Sinkula 1994, Narver and Slater 1995). A learning orientation is a necessary organizational resource to achieve a competitive advantage (Day 1994, Dickson 1996). Recent empirical contributions in this area have provided construct variables which are measurable for learning orientation (commitment to learning, open mindedness and shared vision)(Sinkula, Baker and Noordewier 1997).

Performance measures have varied in the literature, and new measures have been introduced, such as marketing dynamism, defined as the rate of change in marketing programs (Sinkula, Baker and Noordewier 1997).

\subsubsection{Hypotheses}

H01: There is a negative or no linear relationship between learning orientation and organizational performance.

H01a: There is a negative or no linear relationship between commitment to learning and performance.

\subsection{Sample And Data Collection}

Sample and data collection are modeled on the research of Sinkula, Baker and Noordewier (1997) and Baker and Sinkula (1999). In their 1997 article, Sinkula, Baker and Noordewier (1997) determined that upper-level managers should be included in the research domain. Individuals selected cover a wide range and diversity of industries (Sinkula, Baker and Noordewier, 1997). In their 1999 article, Baker and Sinkula included both marketers and non-marketers. However, like their previous research only those holding vice presidential rank or above were included (Baker, Sinkula,and Noordewier 1997). Baker and Sinkula (1999) further stipulated that only organizations with more than $\$ 500$ million in sales were sampled.

The major difference between the 1997 and 1999 research was that the 1999 sample was a cross-sectional sample rather than a more focused sample. This research will follow the direction of Baker, Sinkula and Noordewier (1997) to test Learning Orientation.

All questions/constructs have been selected from previously published articles and do not require permission to use these questionnaires. Each questionnaire contained a coded identifier so that individuals who did not respond within four weeks can be sent a reminder to complete the questionnaire.

Eight hundred and seventy-six questionnaires were sent to a list of executives as obtained from the American Marketing Association. Individuals selected will follow identical criteria as described in Sinkula, Baker and Noordewier (1997). The criteria used by Sinkula, Baker and Noordewier (1997) was a random sample selected from the American Marketing Association membership roster for the current year. Those individuals selected would be considered senior members of the organizational hierarchy, based on title. For this research, individuals were 
selected from the 2001 membership roster. The researcher is a member in good standing of the American Marketing Association. Of those sent, 279 were returned and 218 were usable for the research. A response rate of $32 \%$ was obtained.

\subsection{Performance Construct}

\subsubsection{Validity And Reliability}

Performance has been measured using many different variables to evaluate the constructs to be tested in this research. Narver and Slater (1990) measured performance as return on assets (ROA) relative to the competition and found a positive relationship between ROA and market orientation. Jaworski and Kohli (1993) used subjective and objective measures of performance: 1) overall performance of the business and 2) overall performance relative to major competitors. This measure is used by Kohli and Jaworski (1993) is again utilized in the research of Baker and Sinkula (1999). Assessment of the performance measures was evaluated by a confirmatory two factor analysis.

Baker and Sinkula (1999) also added 'change in relative market share compared to the largest competitor' as one of the dependent performance variables, which was adapted from Day (1977). The findings revealed that the XMS model explained a significant amount of variance (adjusted $\mathrm{R}^{2}=.168$ ) and the overall performance model explained a greater level of variance than the Kohli and Jaworski (1993) study $\left(\mathrm{R}^{2}=.25\right)$.

For this research, organizational performance factored in a one-dimensional variable (Appendix C) with the two-item scale accounting for over $77 \%$ of the explained variability.

Jaworski and Kohli (1993) used subjective and objective measures of performance: 1) overall performance of the business and 2) overall performance relative to major competitors. These two measures have a high degree of reliability as the alpha value was .83. Deshpande, Farley and Webster (1993) measured performance as compared to the businesses' largest competitor from the perspective of profitability, business size, market share and growth rate, and reflected a Cronbach alpha of .90, also indicative of a high level of reliability. The measure used by Kohli and Jaworski (1993) is again utilized in the research of Baker and Sinkula (1999). Reliability of this two item performance scale indicates a high level of internal consistency at .79. For this research, a reliability coefficient of .74 was obtained for the two item scale measuring performance.

\subsection{Research Findings}

Both performance and learning orientation are multi-dimensional constructs. Performance is comprised of two components, overall performance and performance relative to competition. For this study, both components combined to form one unique factor comprised of two components.

Table 1: Total Variance Explained

\begin{tabular}{|l|c|c|c|c|c|c|}
\hline \multirow{2}{*}{ Component } & \multicolumn{3}{|c|}{ Initial Eigenvalues } & \multicolumn{3}{c|}{ Extraction Sums of Squared Loadings } \\
\cline { 2 - 7 } & Total & $\begin{array}{c}\text { \% of } \\
\text { Variance }\end{array}$ & $\begin{array}{c}\text { Cumulative } \\
\text { \% }\end{array}$ & Total & Vo & Cumulative \\
Variance & 77.069 \\
\hline 1 & 1.541 & 77.069 & 77.069 & 1.541 & 77.069 & \\
\hline
\end{tabular}

Extraction Method: Principal Component Analysis

The principal component analyses, above, confirms the unique factor to describe business performance.

Learning orientation is measured by three components: commitment to learning (Avg_Com); shared vision (Ang_Sv) and open-mindedness (Avg_Om). Each component factored into a one-dimensional construct as described below. 
Table 2: Total Variance Explained

\begin{tabular}{|c|c|c|c|c|c|c|}
\hline \multirow[b]{2}{*}{ Component } & \multicolumn{3}{|c|}{ Initial Eigenvalues } & \multicolumn{3}{|c|}{ Extraction Sums of Squared Loadings } \\
\hline & Total & $\begin{array}{c}\% \text { of } \\
\text { Variance }\end{array}$ & $\begin{array}{c}\text { Cumulative } \\
\%\end{array}$ & Total & $\begin{array}{c}\% \text { of } \\
\text { Variance }\end{array}$ & $\begin{array}{c}\text { Cumulative } \\
\%\end{array}$ \\
\hline 1 & 3.839 & 63.984 & 63.984 & 3.839 & 63.984 & 63.984 \\
\hline 2 & .935 & 15.583 & 79.567 & & & \\
\hline 3 & .543 & 9.049 & 88.615 & & & \\
\hline 4 & .289 & 4.819 & 93.435 & & & \\
\hline 5 & .212 & 3.535 & 96.970 & & & \\
\hline 6 & .182 & 3.030 & 100.000 & & & \\
\hline
\end{tabular}

Hypothesis H01 tests whether there is a linear relationship between learning orientation and performance. A correlation analysis tests whether two variables are linearly related. Table 3 displays the results of these analyses.

An average response is calculated over the statements for each original construct. A positive linear relationship exists between all dimensions organizational performance and learning orientation. All sub-hypotheses, associated with each unique component are rejected (Table 3). Therefore, H01 is rejected.

Hypothesis H01 suggests a relationship exists between performance and learning orientation is rejected. This result lends support to the postulated effect and necessary influence of learning orientation on performance by learning orientation serving as a change catalyst, transitioning market orientation from a knowledge producing behavior to a knowledge questioning behavior (Narver and Slater 1994, Hurley and Hult 1998, Baker and Sinkula 1999).

This linear relationship between learning orientation and performance also supports the presumed intervening effect of learning orientation on necessary behavioral changes within the organization for improved performance (Fiol and Lyles 1985, Senge 1990, Garvin 1993, Sinkula 1994).

Table 3: Correlation Analysis - Hypothesis H01

\begin{tabular}{|c|c|c|c|c|c|c|}
\hline Variable & & Perf & $\begin{array}{c}\text { Market } \\
\text { Share }\end{array}$ & Avg_Com & $\begin{array}{c}\text { Avg_ } \\
\text { SV }\end{array}$ & Avg_OM \\
\hline Perf & $\begin{array}{l}\text { Pearson Correlation } \\
\text { Sig. (2-tailed) } \\
\text { N }\end{array}$ & $\begin{array}{c}1.000 \\
218 \\
\end{array}$ & $\begin{array}{l}.450 * * \\
.000 \\
215 \\
\end{array}$ & $\begin{array}{l}.289 * * \\
.000 \\
218 \\
\end{array}$ & $\begin{array}{l}.218 * * \\
.000 \\
218 \\
\end{array}$ & $\begin{array}{l}.158 * * \\
.000 \\
218 \\
\end{array}$ \\
\hline $\begin{array}{l}\text { Market } \\
\text { Share }\end{array}$ & $\begin{array}{l}\text { Pearson Correlation } \\
\text { Sig. (2-tailed) } \\
\text { N }\end{array}$ & $\begin{array}{l}.450^{* *} \\
.000 \\
215 \\
\end{array}$ & $\begin{array}{c}1.000 \\
\dot{2} \\
215 \\
\end{array}$ & $\begin{array}{l}.197 * * \\
.000 \\
215 \\
\end{array}$ & $\begin{array}{l}.218^{* *} \\
.004 \\
215 \\
\end{array}$ & $\begin{array}{l}.158^{* *} \\
.001 \\
215 \\
\end{array}$ \\
\hline Avg_Com & $\begin{array}{l}\text { Pearson Correlation } \\
\text { Sig. (2-tailed) } \\
\text { N }\end{array}$ & $\begin{array}{l}289 * * \\
.000 \\
215 \\
\end{array}$ & $\begin{array}{l}.197 * * \\
.000 \\
218 \\
\end{array}$ & $\begin{array}{c}.1 .000 \\
218 \\
\end{array}$ & $\begin{array}{l}.465 * * \\
.000 \\
218\end{array}$ & $\begin{array}{l}.428 \\
.000 \\
218 \\
\end{array}$ \\
\hline $\begin{array}{l}\mathrm{Avg}_{-} \\
\mathrm{SV}\end{array}$ & $\begin{array}{l}\text { Pearson Correlation } \\
\text { Sig. (2-tailed) } \\
\text { N } \\
\end{array}$ & $\begin{array}{l}.346^{* *} \\
.000 \\
215 \\
\end{array}$ & $\begin{array}{l}.218^{* *} \\
.004 \\
215 \\
\end{array}$ & $\begin{array}{l}.465 * * \\
.000 \\
218 \\
\end{array}$ & $\begin{array}{c}1.000 \\
218\end{array}$ & $\begin{array}{l}.559 * * \\
.000 \\
218 \\
\end{array}$ \\
\hline Avg_OM & $\begin{array}{l}\text { Pearson Correlation } \\
\text { Sig. (2-tailed) } \\
\text { N }\end{array}$ & $\begin{array}{l}.231 * * \\
.000 \\
215\end{array}$ & $\begin{array}{l}.158^{* *} \\
.001 \\
215\end{array}$ & $\begin{array}{l}428 * * \\
.000 \\
218\end{array}$ & $\begin{array}{l}.559^{* * *} \\
.000 \\
218\end{array}$ & $\begin{array}{c}1.000 \\
\dot{2} \\
218\end{array}$ \\
\hline
\end{tabular}

A new measure of performance was introduced in the research of Baker, Sinkula and Noordewier (1997); marketing program dynamism (DYNAMISM), which is directly adapted from Achrol and Stern (1988). Although 
Achrol and Stern (1988) defined dynamism as only one of three derived subconstructs of environmental dynamism, the scale reliability of the dynamism of marketing programs (DYN-MP) measured .763. Confirmatory factor analysis was conducted to indicate scale reliability and resulted in 'moderately good to high' consistency levels (Achrol and Stern 1988). For this study, the three components of market dynamism factor into one unique construct as displayed in Table 4.

Table 4: Total Variance Explained

\begin{tabular}{|l|c|c|c|c|c|c|}
\hline \multirow{2}{*}{ Component } & \multicolumn{3}{|c|}{ Initial Eigenvalues } & \multicolumn{3}{c|}{ Extraction Sums of Squared Loadings } \\
\cline { 2 - 7 } & Total & $\begin{array}{c}\text { \% of } \\
\text { Variance }\end{array}$ & $\begin{array}{c}\text { Cumulative } \\
\text { \% }\end{array}$ & Total & $\begin{array}{c}\text { \% of } \\
\text { Variance }\end{array}$ & $\begin{array}{c}\text { Cumulative } \\
\text { \% }\end{array}$ \\
\hline 1 & 2.213 & 73.774 & 73.774 & 2.213 & 73.774 & 73.774 \\
2 & .547 & 18.223 & 91.997 & & & \\
3 & .240 & 8.003 & 100.000 & & & \\
\hline
\end{tabular}

Extraction Method: Principal Component Analysis

The research of the DYNAMISM variable in the research of Baker, Sinkula and Noordewier (1997) reflects a very similar coefficient alpha of .77, indicating a high reliability of this measure.

The dynamism measurement, though relatively new and tested on a limited basis, appears to also have an effect on an organizations' performance, although dynamism reveals short term incremental learning resulting from changes in strategies. The ability of an organization to change frequently as situations dictate requires responsiveness to organizational learning, which enhances an organizations' competitive advantage (Hosely, Tau, Levy and Tan 1994). Dynamism appears to be an appropriate measure of the incremental learning that may occur in an organizations' pursuit of long term superior performance.

\section{Implications}

The results of this study reveal that both long term and short term measures of organizational learning have an effect on organizational performance. The short term performance measure of dynamism may also be interesting to measure during periods of stability and instability in the competitive environment, and analyzed for different industries specifically. The frequency at which product, sales, promotion and advertising strategies are changed may vary greatly between industries during times of perceived environmental volatility.

Also, since dynamism is a short term measure of performance, it would be interesting to correlate the degree of dynamism to the degree of learning achieved with the organization. Learning orientation, as described in previous research as a change agent would theoretically have a significant impact on the degree of dynamism as a measure of the change that occurs as a result. 
Notes 